Theories \& Applications, the International Edition

Printed Version: (ISSN 2090-5262)

Online Version: (ISSN 2090-5270)

November 2012, Volume 2, No. 3 Pages (117 - 125)

\title{
State and Trait Anger and Its Relationship to the Sport Orientation of Some Combat Sports Players
}

\author{
Nehal Salah Eldin Obada*
}

\begin{abstract}
:
The purpose of this study was to examine anger as a state and as a trait of some individual combat sports players (Karate, Judo, Taekwondo, Fencing.) and its relationship to sport orientation (competitiveness - win orientation - goal orientation ). One hundred and forty, 35 players from each sport, from teams throughout Sharqia, Egypt, participated in the study. The players' ages ranged from 15-18 years, and their competitive experience ranged from 2-5 years. The State Trait Anger Inventory (Spielberger, London) and The Sport Orientation Questionnaire (SOQ) were used. Data analysis showed significant direct correlation relationships between trait anger and sport orientation dimensions and between state anger and win and goal orientation of all the combat sports players in general. Significant differences were also found between players characterized by trait anger in all the sport orientation dimensions. There are also significant differences between the players who are characterized by state anger in win orientation.
\end{abstract}

\section{Introduction:}

Sport is one of the activities the individual practices and has a close relationship to the multiple intense emotions. It is also characterized by its emotional appeal that forms the positive effect on the personality. These emotions play an important role in the life of the individual as they are related to motives and needs and the multiple activities he practices. All types of learning, play, creative activities or different social relationships are colored by their distinctive emotions.

The emotional experiences associated with the sport activity are divided into pleasant, such as success, security and pleasure, and unpleasant, such as fear, anxiety and distress. Both types of emotions have positive or negative effect on the biological operations and behavior and the intensity of this effect varies from a player to another.

The emotional state of a person depends on the distinctive personal characteristics, the sports activity practiced, the competition type, the

\footnotetext{
* Assistant Professor, Social \& Educational Sciences Department, Faculty of Physical Education for Girls, Zagazig University, Egypt.
}

competition setting, the audience, the administrators in charge and everything related to the competition and the opponent. Anger, fear and anxiety are the most important emotions (10: 353-358).

Most athletes agree that they experience different degrees of fear, anxiety and anger and these emotions affect their performance. Some can control these emotions whilst others cannot and this, in turn, affects their performance negatively, especially during the competing.

Like fear, happiness and sadness, anger is a universal emotion. There is no such player who has not experienced anger especially the players who practice sports characterized by direct contact with the opponent and affected by the characteristics of the audience and the referees. These aspects produces that emotion that result in conscious emotional response associated by expressive movements and gestures whose period differ according to the stimulus's type and intensity and the character of the player.

"Ahmed Fawzy" (2003) states that "emotion" is an excitement state individuals experience when confronted by a competitive situation that generates fear, anxiety, anger, sadness, pleasure happiness or enthusiasm. The intensity of the 
emotion depends on perception and effect of the competitive situation that aroused it (1:231).

Anger itself is not the problem but rather in its consequences. "Novaco" (1975) thinks that "anger provides behavior with energy increases the intensity of our reactions, leads to a defensive reaction to the ego threat and provokes aggression. It also strengthens the feeling of control and reflects the negative feeling towards the current situation (15).

In addition to the consequent damage or harm, there are two perceptive operations to explain the anger arousal: intentionality and expectedness "Ben-Zur,H. \& Brezentz,S" (1991) Intentionality refers to all what is related to the explanation or analysis of the current and past situations, the person's evaluation of his ability to manage the threat and the imposed demand. Expectedness refers to the personal evaluations as a result of this particular situation (9: 12).

"Osama Rateb" (1995) believes that if we analyze the psychological characteristics of the sport we will find that the individual sports players have high rates of emotions compared to the team sports players, as the first group respond to the competitive situation as a personal threat and take the consequences of their performance directly. Further, the individual sports requires a high degree of psyching up in a short time as the playtime of these sports does not exceed minutes such as the combat sports and weighting lifting. The players in these activities experience very intense emotions (17: 40-47).

"Robert Weinberg \& Daniel Gould" (2003), "Haward Nixion" (2001), "David M., Robyn . J." (2001), "Mohamed Alaawy" (1998), and "Osama Rateb" (1994) state that "emotion in the competitive sport field is a readaptation of the physical processes that happen automatically as a response to the competitive behavioral situation".

"Lutwak et all" (2001) add that most expectations that seem to express anger are related to the negative feeling of the future success as anger is the hardest state to control because it fills up the mind of the person with all the persuasive reasons to outburst on the triggering situation.
"Lutwak et all" (2001) also mentions that physiologically speaking anger is emotional state that can take control of the person and results in psychological and physical disturbances making the person lose control on his words and actions. "Osama Rateb" confirms that anger makes a lot of negative physiological changes in the body. When man gets angry, a lot of confusing signals reaches the Pituitary Gland which, in turn, sends chemical signals to the Adrenal Glands which increase the secretion of Adrenal that upsets all the chemical and physiological standards of the body especially if it happens before or during the competition. This increases the Glycogenolysis in the liver, the strategic store for the body, the decomposition of proteins into amino acids and the oxidation of fatty acids. All these processes take place to increase the amount of Glucose which is burned to provide the body with the energy required for the emotion. This is considered as a waste of the energy resources the player needs during the competition (8:641$655)$.

Although sport competitions focus on winning under organizing laws and regulations, the articles of the sport laws can be interpreted differently in a way that allows players to violate them and be violent enough to provoke the aggressive behavior of their opponents. Therefore, players, especially players of individual sports, should try to control their personal emotions regarding the aggression of their opponents, their relationships inside and outside the court, the audience and the management style (17:14-16).

The researcher believes that anger trait is one of the emotions that appear intensely in the individual sports players. However, it has not had the proper attention and study in sports activity despite its effect on the sport performance as it leads to be the player misjudge or quickly judged. Anger arises when the player perceives a direct intentional attack on his personal values or standards.

Through watching and observing the competitive sports in the Olympic and domestic tournaments, the researcher noticed the increasing anger in the fans and the top players. One of the examples is "John McEnroe", the famous tennis player who has outbursted in 
several international matches. Another example is the Egyptian wrester who was disqualified by the organizing committee of Athens Olympic Games because he was overwhelmed by anger. The third example is the weight lifter in the most recent games who, after receiving his medal, put it on the podium. Combat coaches in the collegiate tournaments organized by the college have also repeatedly complained about the anger behavior of the young athletes and their unwillingness to participate shortly after being exposed to emotional situations (23), (13: 359-365).

All that inspired the researcher to study anger as a trait and a state and its relationship to the sport orientation of some combat sports players due to lack of studies dealing with that topic in the Arab and Egyptian settings, only two studies dealt with of the topic. The first study was done by "Taher Hasan" (2006) (21) to examine the differences between anger as a state and as a trait of some water sports (swimming, diving, water ball) players. The second study was carried out by "Samy Abd Al Salam" (2008)(19) to identify anger as trait and a state for some grapplers. Moreover, anger has a great effect on involvement in competitive sport and no other study has dealt with the effect of anger on the competitive orientation.

\section{Significance of the study:}

1. The current study is important as the reactions of the emotional behavior of anger results in negative feelings and may disqualify players or affect their performance negatively.

2. The study sheds some light on the emotional behavior of anger of combat sports players as an emotional problem that has to be tackled.

3. Identifying anger as a trait and as a state for the combat sports players and coaches' management of its consequences and its relationship to the competitive orientation, as a trial to understand and manage it.

\section{The study Terms:}

Anger: Anger is defined by "Lararus" (1985) as a storming violent reaction that depends on the person's evaluations of the harmful environmental events (9:9).
State anger: State anger is defined by "Spielberger" (1983) as an affection state of subjective feelings such as stress, tension and rage (9:9).

Trait anger: Quantitatively, trait anger is defined as the frequency of feeling angry at a specific time. A person with high trait anger tends to respond with anger to most or all situations (9:9).

Competitiveness: The wish to persist and struggle to succeed in sports competitive situations and enjoy competing with others to win (10:333).

Goal Orientation: "Kremer \& Scully" (1994) defines goal orientation as determination or conscious intention or what the person sets to achieve (10:296).

Win Orientation: Focusing on comparing the player's level with other players (10:292).

\section{Purposes of the study:}

The main purpose of the study is identifying anger as a state and as trait for some individual combat sports players (Karate, Judo, Taekwondo, Fencing) and its relationship to sport orientation (competitiveness - win orientation - goal orientation).

\section{The Hypotheses:}

1. There is a significant correction relationship between anger as a trait and as state and sport orientation with its three dimensions.

2. There are statistically significant differences between the top and the lower quartiles that are distributed according to the trait anger a state anger in the sport orientation dimensions (competitiveness - win orientation - goal orientation).

\section{Procedures:}

\section{Approach:}

The phenomenological approach was used as it suited the purposes of the study.

\section{Sample:}


One hundred and forty combat players (Karate, Judo, Taekwondo, Fencing), 35 players from each sport, from teams throughout Sharqia, Egypt, participated in this study. The players' ages ranged from 15-18 years, and their competitive experience ranged from 2-5 years. Five players from each sport took part in the pilot study to standardize the instruments.

\section{Methodology:}

\section{Instruments:}

1. The State Trait Anger Inventory (Spielberger, London) (Appendix 1)

The inventory was used to measure trait anger, state anger, and anger expression. The 30-item inventory consists of two parts: part one measures anger as a personal trait that is relatively stable, part two measures anger as an emotional state that varies according to the situation, type of person, intensity and frequency. "Mohamed El Sayed and Fawqia Hasan" Arabicized it and calculated its scientific coefficients in the Egyptian Environment (9:34-37)

\section{The Sport Orientation Questionnaire (SOQ) (Appendix 2)}

The Questionnaire was designed by Dianna Gill (1993) to measure the three dimensions of sport motivation orientation: win orientation, competitiveness, goal orientation. The 25-item questionnaire comprises 13 items for competitiveness, 6items for win orientation, 6items for goal orientation. It was Arabicized by "Mohamad Alaawy" (12:191 -195).

\section{Standardization:}

The State Trait Anger Inventory and The Sport Orientation Questionnaire were standardized by the researcher in the pilot study on 8th and 9th of August, 2011. The Cronbach's alpha, the internal consistency and the split-half were calculated and revealed high degree of validity and reliability (Appendix 3).

\section{Application on the main sample:}

After making sure of the high degree of validity and reliability, the questionnaires were used with the main sample from 14th through 25 th of August; 2011.The players' responses were then prepared for the statistical manipulation.

\section{The statistical coefficients:}

Mean medium, standard deviation, Kurtosis, simple correlation coefficients, and $\mathrm{T}$ - Test to calculate the differences significance

\section{Results:}

Table 1

Statistical Description of the sample in the study variables

$(N=120)$

\begin{tabular}{|l|l|c|c|c|c|}
\hline $\mathrm{N}$ & item & Mean & Medium & SD & Kurtosis \\
\hline 1 & State anger & 36.28 & 36.50 & 6.098 & .326 \\
\hline 2 & Trait anger & 34.97 & 35.00 & 6.557 & -.021 \\
\hline 3 & Competitiveness & 52.28 & 55.50 & 9.233 & -1.519 \\
\hline 4 & Win orientation & 24.63 & 26.00 & 4.916 & -1.579 \\
\hline 5 & Goal orientation & 25.25 & 26.00 & 3.969 & -1.889 \\
\hline
\end{tabular}

The table shows that Kurtosis coefficients of the $(-3,+3)$ range. That proves that the sample was study sample in the variables values were in the a homogenous normal society in these variables. 
Table 2

Correlation Coefficients between the variables chosen for each sport ( $N=30$ for each sport)

\begin{tabular}{|c|c|c|c|c|}
\hline Sport & Variables & Competitiveness & Win Orientation & Goal Orientation \\
\hline \multirow{2}{*}{ Karate } & State anger & -0.179 & $0.482^{*}$ & $0.461^{*}$ \\
\cline { 2 - 5 } & Trait anger & $-0.504^{*}$ & 0.145 & 0.208 \\
\hline \multirow{2}{*}{ Judo } & State anger & $0.457^{*}$ & $0.665^{*}$ & $0.610^{*}$ \\
\cline { 2 - 5 } & Trait anger & -0.158 & -0.445 & $0.450^{*}$ \\
\hline \multirow{2}{*}{ Taekwondo } & State anger & 0.008 & 0.043 & $-0.202^{*}$ \\
\cline { 2 - 5 } & Trait anger & 0.115 & $0.530^{*}$ & 0.124 \\
\hline \multirow{2}{*}{ Fencing } & State anger & 0.289 & 0.039 & 0.129 \\
\cline { 2 - 5 } & Trait anger & 0.245 & 0.248 & $0.455^{*}$ \\
\hline
\end{tabular}

*The correlation coefficient is significant at $(0.05) \quad$ is .444

The table shows some statistically significant between the variables and insignificant correlation relationships in

Table 3

The correlation coefficients between anger variables and sport orientation dimensions for the overall study sample $N=120$

\begin{tabular}{|c|c|c|c|}
\hline Variables & Competitiveness & Win orientation & Goal Orientation \\
\hline State anger & $0.321^{*}$ & $0.297^{*}$ & $0.306^{*}$ \\
\hline Trait anger & 0.172 & $0.214^{*}$ & $0.228^{*}$ \\
\hline
\end{tabular}

*The correlation coefficient significance at $(0.05)$ is $(0.195)$

The table shows statistically significant dimensions (competitiveness - win orientation correlation relationships for the overall study goal orientation). And state anger and goal sample between the trait anger and orientation orientation and win orientation.

Table 4

The significance of the differences between the top and lower quartiles in trait anger / state anger inventory $(N=30$ each $)$

\begin{tabular}{|c|c|c|c|c|c|c|c|c|}
\hline \multirow{2}{*}{$\mathrm{n}$} & \multirow{2}{*}{ Variables } & \multicolumn{2}{|c|}{ Top Quartile } & \multicolumn{2}{c|}{ Lower Quartile } & \multirow{2}{*}{ Difference } & \multirow{2}{*}{ T Value } & \multirow{2}{*}{ P-value } \\
\cline { 3 - 6 } & & $\mathrm{M}$ & $\mathrm{SD}$ & $\mathrm{M}$ & $\mathrm{SD}$ & & & \\
\hline 1 & State anger & 35.82 & 2.56 & 26.29 & 2.37 & 9.53 & 14.662 & .000 \\
\hline 2 & Trait anger & 34.17 & 2.65 & 24.88 & 2.71 & 9.29 & 13.271 & .000 \\
\hline
\end{tabular}

T value at (0.05) equals 2

The table shows the significance of the in anger trait/anger state inventory for the top differences between the top and lower quartiles one.

Table 5

The significance of the differences between the top and lower quartiles distributed according to the trait anger in the sport orientation dimensions $(N=30$ each $)$

\begin{tabular}{|c|l|l|l|l|l|l|l|l|}
\hline \multirow{2}{*}{$\mathrm{n}$} & \multirow{2}{*}{ Variables } & \multicolumn{2}{|c|}{ Top Quartile } & \multicolumn{2}{l|}{ Lower Quartile } & \multirow{2}{*}{ Difference } & \multirow{2}{*}{ T Value } & \multirow{2}{*}{ P-value } \\
\cline { 3 - 7 } & & $\mathrm{M}$ & $\mathrm{SD}$ & $\mathrm{M}$ & $\mathrm{SD}$ & & & \\
\hline 1 & Competitiveness & 53.73 & 8.72 & 47.07 & 10.29 & 6.67 & 2.71 & .009 \\
\hline 2 & Win Orientation & 26.40 & 3.05 & 21.60 & 5.67 & 4.80 & 4.09 & .000 \\
\hline 3 & Goal orientation & 25.80 & 2.43 & 23.00 & 5.39 & 2.80 & 2.59 & .012 \\
\hline
\end{tabular}

T value at (.05) equals 2

The show shows the significance of the sport orientation variable (competitiveness- win differences between the top and lower quartiles orientation - goal orientation)

distributed according to the trait anger in the 
Table 6

The significance of the differences between the top and lower quartiles distributed according to the state anger in the sport orientation dimensions

$(N=30$ each $)$

\begin{tabular}{|c|c|c|c|c|c|c|c|c|}
\hline \multirow{2}{*}{$\mathrm{n}$} & \multirow{2}{*}{ Variables } & \multicolumn{2}{|c|}{ Top Quartile } & \multicolumn{2}{|c|}{ Lower Quartile } & \multirow{2}{*}{ Difference } & \multirow{2}{*}{ T Value } & \multirow{2}{*}{ P-value } \\
\cline { 3 - 6 } & & $\mathrm{M}$ & $\mathrm{SD}$ & $\mathrm{M}$ & $\mathrm{SD}$ & & & \\
\hline 1 & Competitiveness & 51.43 & 9.57 & 51.40 & 7.22 & .033 & .015 & .988 \\
\hline 2 & Win Orientation & 26.50 & 2.85 & 23.70 & 3.94 & 2.80 & $3.15^{*}$ & .003 \\
\hline 3 & Goal orientation & 25.87 & 2.29 & 24.50 & 3.32 & 1.37 & 1.86 & .068 \\
\hline
\end{tabular}

T value at (.05) equals 2

The table shows the significance of the differences between the top and lower quartiles distributed according to the state anger in the win orientation variable.

\section{Discussion:}

Table (2) that is related correlation coefficients between the state anger and trait anger variables and the sport orientation dimensions for each sport separately shows the following:

Karate Players: The table shows significant correlation relationships between state anger and win orientation and goal orientation and between state anger and competitiveness. This finding is consistent with what Nakayama (1986) suggested that karate, albeit a selfdefense sport in all the sense of the word, involves persistence, fitness and strength. It depends on acquiring players self-confidence, ability to control their emotions and it helps them discharge inner the energy. Tommy (1987) also states that karate develops the personality traits through training to overcome any penalty by the game organizing rules. Additionally, it acquires players respect, discipline and order as it is a means of self-defense with the bare hand (14: 11) (22: 8).

Judo Female Players: The same table shows significant correlation relationships between trait anger and all the sport orientation dimensions (competitiveness - goal orientation win orientation) and between state anger and win orientation and goal orientation. The researcher attributes that to the fact that trait anger helps judo players change it into an explosive power in performance and enables them to control the beginning of anger and follow the commonly accepted manners in winning or defeat. The emotional area therefore, should have the same attention the cognitive and skill areas to turn anger into positive results to achieve the goal.

Taekwondo Players : The table shows significant correlation relationships between state anger and win orientation. This is due to the fact that Taekwondo is less emotional than the other sports.

Female Fencers: The table shows significant correlation relationships between state anger and goal orientation. The research attributes that to high level of determination, self-control and an ability to take quick decisions fencers have.

Table 3 shows the significance of the correlation relationships between trait anger and all the dimensions of the sport orientation (competitiveness -goal orientation - win orientation).

This finding means that competitiveness and win and goal orientation of combat female players are basically related to trait anger and state anger. It can therefore be inferred that the nature of combat sports (Fencing, Taekwondo, Judo, Karate) requires players to have some emotional traits such as anger, either trait or state, due to the alert and motivation state to win, which varies from a person to another and a sport to another. Players of the sports in question are exposed to emotions that result in an emotional response accompanied by expressive gestures whose period depends on the stimulus's type and intensity and the unique personal characteristics of the player. This is consistent with the nature of the combat sports which are characterized by direct contact with the opponent.

This finding is also consistent with what he Osama Rateb's (1995) suggestion that individual sports players experience higher level of emotion than their counterparts in the team sports. It also corroborates with the findings of 
Samy Abd Al Salam's (2008) study that grapplers have both the trait and state anger.

This finding confirms the first hypothesis which states that there is a significant correction relationship between anger as a trait and as state and sport orientation with it three dimensions (competiveness - win orientation - goal orientation).

Tables $(4,5,6)$ show that the college sample (the combat sports players) is divided according to their scores on the trait anger and state anger variables. Calculating the significance of the differences between the lower and top quartiles reveals that the differences were for the top quartile. Therefore, the researcher compared the lower and top quartiles players in the competitive orientation dimensions (competitiveness - goal orientation - win orientation).Table 5 indicates that the differences were for top quartile players, who are divided according to the scores of trait anger , in all the competitive orientation dimensions (competitiveness- goal orientation - win orientation).Table 6 displays the differences between the quartiles that are divided according to the state anger and shows that the differences were for the top quartile in measuring the win orientation.

This finding means that there is an indirect relationship between anger as a trait for the combat sports players and the sport orientation dimensions (competitiveness- win orientation goal orientation) and between anger as state for those players and win orientation. This is confirmed by the significance of the differences between the two quartiles. This can be accounted for by the fact that players with high scores in trait anger are win, goal and competiveness oriented more than those with low scores. Players with high score in state anger are also more win oriented.

Emotional experiences in sports positively affect the biological and behavioral processes creating a sport orientation ( competitiveness win orientation - goal orientation).This is consistent with the ideas of Robert Weinberg \& Daniel Gould (2003),Mohamed Alaawy (1998), Osama Rateb (1994) who suggested that emotions in competitive sport is a readaptation of the biological processes that take place as a response to the competitive behavioral situation and this is what characterizes players of combat sports players such as Karate, judo, Taekwondo and fencing.

The produced effect varies between the players of different sports according to their score in trait anger and state anger. That supports the outcomes of Taher Hasan's study (2006) that there are differences between the trait anger and state anger between the water sports players and confirms the differences that appeared for the combat players in this study.

Generally, the results of comparing the two quartiles confirms that players with high scores in state anger have high scores in competitive orientation (competiveness - win orientation goal orientation) and players with high scores in state anger have high scores in win orientation. That confirms the relationship between the two variables of anger and the sport orientation dimensions.

"Novaco" states that reinforcing anger management should focus on the rational cognitive, physical, emotional and behavioral responses. "Deffenbacher" (1996) suggested that in order to achieve positive effects, there should be a condensed program that includes a group of procedures such as relaxation techniques and training on social skills. "Johon\& Bryan" (1997) also recommend having a sport psychologist to train players on how to dealing the emotional responses during and outside the competition.

This finding confirms the second hypothesis which states that there are statistically significant differences between the top and the lower quartiles that are distributed according to the trait anger a state anger in the sport orientation dimensions (competitiveness - win orientation - goal orientation).

\section{Conclusions:}

In the light of the study objectives, outcomes and within the study sample limitations, the following can be concluded:

1. There are direct statistically significant correlation relationships between state anger and all the sport orientation dimensions and between win orientation and goal orientation of the karate female players. 
2. There are direct statistically significant correlation relationships between state anger and sport orientation dimensions and between state anger and goal orientation of the Judo players.

3. There are statistically significant correlation relationships between state anger and win orientation of Taekwondo players.

4. There are statistically significant correlation relationships between state anger and goal orientation of the fencers.

5. There are direct statistically significant correlation relationships between trait anger and sport orientation dimensions and between state anger and win and goal orientation of all the combat sports players in general.

6. There are statistically significant differences between the players characterized by trait anger in all the sport orientation dimensions.

7. There are statistically significant differences between the players who are characterized by state anger in win orientation.

\section{Recommendations:}

In the light of the study objectives .conclusions and within the study sample limitations, the following can be recommended:

1. Selecting the combat sports players should be based on the findings of the study concerning the state anger and trait anger and sport orientation dimensions.

2. The individual differences in the emotional variables (anger) and sport orientation should be taken into consideration. They should also be developed to achieve the highest technical and training performance possible.

3. The psychological training programs should include developing the social skills and relaxation techniques. They should also focus on the rational, cognitive, physical, emotional and behavioral responses in order to manage the anger needed by combat sports players to achieve their goal.

4. Having a sport psychologist to train players on how to dealing the emotional responses during and outside the competition.
5. Further studies that deal with other emotional variables and their relationship to the performance level are needed.

\section{References:}

1. Ahmed Amin Fawzy. (2003). Principles of Sport Psychology: Concepts \& Applications .Dar Al Fekr Al Arabi, Cairo.

2. Amin Al Khouly. (1994). Fair Play for All. Dar Al Fekr Al Arabi series in Physical education. Dar Al Fekr Al Arabi, Cairo.

3. Andrew Yionnakis, Merrilly, Melnick. (2001). Contemporary issues in sociology of sport Olympic. Review : Human Kinetics

4. Collis Steven Haily. Jo. (1992). The anger expression scale: correlations with the state, Trait personality. Journal of Education and Psychology. Cal Measurement, Vol.(42) No., (2)

5. Deffenbacher, Jerry. (1996). Anger reduction in early adolescents Journal of Counseling psychology Vol.34, No.2, P.149-157.

6. Jean Q.Davise. (2003). Anger aggression and adolescent, Yale- New York

7. Johon, F.A.\& Bryan. R.K. (1997). Aggression Der fourmanc variables and anger self- Report in Ice Hockey Players. . The Journal of Psychology.

8. Lutwak Nita and others. (2001). Shame and Guilt and relationship to positive expectations and anger expressiveness adolescence, Vol. 36 , No.144, P.641-655

9. Mohamed El Sayed Abdel Al Rahman \& Fawqia Hassan Abd Al Hamid .(1998).State Anger \& Trait Anger Scale. Qibaa Publishing House

10. Mohamed Hassan Alaawy. (1998). Approach to Sport Psychology. Al Ketaab Publishing House. Cairo.

11. Mohamed Hassan Alaawy. (1998). Psychology of Training, Aggression and Violence in Sport. Al Ketaab Publishing House. Cairo.

12. Mohamed Hassan Alaawy. (1998). Psychological tests Encyclopedia for althlets. Al Ketaab Publishing House. Cairo. 
13. Mohamed Hassan Alaawy. (2002). Education \& Health. The Scientific Research Psychology of Training and Sport Competition. Dar Al Fekr Al Arabi. Cairo.

14. Nakayama, M. (1986). Best karate Fundamentals vols2, Kodanscha international co., New York.

15. Novaco, R.W. (1975). Anger control, the development and evaluation of an experimental treatment, Lexington, M.A., D.C. health and Co.

16. Osama Kamel Rateb. (1994). The Technical Bases of Setting a Goal in the Sport Field. Dar Al Fekr Al Arabi, Cairo.

17. Osama Kamel Rateb. (1995). Sport Psychology. Dar Al Fekr Al Arabi,Cairo.

18. Robert S. Wainberg, Daniel Gould. (2003). Foundations of sport and exercise psychology 3rd edition package, Human kinetics.

19. Samy Abdel Salam Abdel Latfi Askar. (2008). State Anger and Trait Anger of Grapplers. The First Conference of Physical

Volume 3. Kuwait.

20. Spielberger. C.D., Jacofs, G., Russel , S. \& Crane R.S. (1983). The state Trait anger scale. (in)J.N.B Butchar and C.D. Spielberger (eds) adnances in personality assessment vol., 2, pp: 159-187, Lawrence Elbaum associates , inc.

21. Taher Hassan Al Shahed. (2006).Identifying the Relationship and the Differences between State Anger and Trait Anger of some Water Sports Players (Swimming, Diving, Water ball).The Psychotherapy Conference Papers. Psychology Department .College of Arts. Monofia University.

22. Tommy, M. (1987). The complete course of karate Guinness. Great Britain

23. Zahraa Abdel Al Moneim Sharqawy. (2002) Evaluative Study of Players' Refrain to Represent Egypt Internationally in the Olympic Individual Sports. Unpublished Doctoral thesis, College of Physical Education for Men, Helwan University, Cairo. 